\title{
Teamwork, myth or reality: community nurses' experience with general practice attachment
}

\author{
LYNN M MCCLURE* \\ From the Leeds Area Health Authority, Western Division, Leeds, UK
}

SUMMARY A survey of 93 community nurses, 48 health visitors, and 45 district nurses was carried out in one area health authority where nurses had been attached to general practice schemes for up to 10 years. The purpose of the study was to determine the nurses' impression of teamwork within their attachment arrangements. Half the group surveyed had either a geographical area or other area health authority responsibilities, or both, in addition to their primary attachment commitment. No structured plan for preparing or evaluating attachment groups had been carried out by the area health authority. Only one third of attached nurses were working from premises shared with other members of the attachment group, and often facilities were poorly designed for teamwork. Health visitors were generally less enthusiastic about attachment and identified more obstacles in developing 'teamwork than did district nurses. Health visitors also tended to stay with individual attachment groups for shorter periods than did district nurses. Most nurses communicated frequently with attachment group members, but these opportunities were unplanned and usually limited to immediate problems of patient care. In a few attachments patterns of communication and collaboration appeared to be non-existant. Despite the problems identified in this study, most respondents prefer attachment to working solely in a geographical area and value their links with the area health authority. Evaluation and positive direction is needed if the primary care team is to develop.

More than a decade ago the concept of "attaching" local authority nursing staff to general practices was a novel and controversial issue within the British health care system. It was hoped that attachment arrangements would encourage the development of a more efficient and comprehensive primary care service based on principles of professional collaboration and teamwork. ${ }^{1}$ By 1975 about $80 \%$ of area health authority nurses were working in some form of attachment arrangement, a dramatic change from the mid-1960s, when less than $5 \%$ were attached to general practices (BLEC Reedy, unpublished data). Such a sweeping conversion from the traditional geographical based method of nurse deployment to the interdependent demands of group work inevitably produced a mixture of enthusiasm and dismay. Initially, the contrasts between the communication patterns and work carried out by attached and unattached community nurses were taken as indicators of "success." For many general practitioners and community nurses, however, the

"Present address: Klinic Community Health Centre, 545 Broadway Avenue, Winnipeg, Manitoba R3 COW 3, Canada. transition from an independent pattern of work to the comparative intimacy of a group was very difficult. At the same time other changes were occuring that had not been foreseen when attachment schemes were started. One was the reorganisation of the National Health Services in 1974. With the introduction of many administrative changes, the role of the medical officer of health was considerably diminished. Thus the description of this role in 1969 as "community physician, organiser, and coordinator of community medical services" soon became inaccurate. ${ }^{1}$

Another important factor since the mid-1970s has been increasing government restraint in health care expenditure. Despite the trend to close hospitals, an increase in the geriatric population, and escalating population and hence social problems in the inner city regions, the numbers of community nurses have been limited. Consequently they have been required to assume larger and more demanding caseloads. Often the need for economy has made it impossible to effect true attachment arrangements as community nurses have been required to assume 68 
additional duties beyond their attachment commitment.

With these changes, the resources and motivation to examine, evaluate, and refine attachment arrangements have not been widely available. Thus a laissez-faire type of approach has evolved with an optimistic, although perhaps naive, assumption that attachment would spontaneously generate primary care teams. While many early studies showed attachment to be preferable to independence, this improvement over the traditional system was no guarantee that development of a coordinated, collaborative team would automatically proçeed.

During the past few years, a more critical approach to attachment has emerged with one writer describing "attachment" as too casual a connotation for the special relationship generated by effective interprofessional group work. ${ }^{2}$ Disillusionment with attachment has prompted some area health authorities to consider dismantling attachments, especially in inner city areas where the population may be transient and unlikely to register with a general practice. Several writers have commented on the difficulties health visitors have experienced in explaining their role and gaining support for it from other members of the attachment group. ${ }^{3-5}$ Another problem has been the dual management system, with the primary team split-the general practitioner operating as an independent contractor whereas community nurses are employed by the area health authority.

Clearly, there are still many unresolved issues and perhaps some threat to the development of primary care teams. This study was initiated by one health authority as a first step in determining how attached staff experience teamwork within their individual attachment arrangements.

\section{Purpose}

The major purpose of this study was to determine how specific factors considered important in the development of primary health care teams were experienced and perceived by a group of attached health visitors and district nurses. These factors have been noted in the relevant reports and include personal characteristics, preparation for attachment, physical premises for teams, communication patterns, professional role definitions, perceptions of teamwork, commitment, and benefits versus problems in provision of patient care services.

The specific aims of the project were to gain some information regarding the present working situation that attachment groups are experiencing; to try and determine if nurses' satisfaction, or lack thereof with attachment schemes is related to the specific factors listed above; to compare the responses of health visitors and district nurses; and to stimulate nurses included in the study to evaluate and look for methods of improving their present attachment arrangement.

\section{Methods}

The study was a descriptive survey and included all full time and part time attached health visitors and district nurses from Leeds Area Health Authority, western division. The study was in two parts. Initially, an open ended questionnaire was developed incorporating questions related to the specific factors discussed under purpose above. This questionnaire was administered by a personal interview with five district nurses and six health visitors randomly selected from the full group of attached health visitors and district nurses. Later a structured questionnaire based on responses from these interviews was developed. Many of the questions required respondents to recall or document details of their attachment practice. In a few questions, however, participants were asked to express an opinion or attitude towards a specific issue. A graduated response system was developed for single answer questions of this type so that responses such as "not, fairly, and very important" were possible. Where multiple answers were to be considered, a category of "other" and instruction to specify was included. Therefore, when the structured responses were inadequate or inappropriate, participants were encouraged to respond with their own opinions and in their own words. The questionnaire was reviewed with the nurses concerned and distributed at a special staff meeting. The questionnaire was completed independently; participation was voluntary and questionnaires were anonymous.

\section{Results}

The results are based on the responses to the structured questionnaires completed by 93 attached community nurses (48 health visitors and 45 district nurses). The total number of possible participants was 98 so that a high response rate $(95 \%)$ was achieved. The actual number of completed questionnaires was higher than the number of participants (97 as opposed to 93 ) as one health visitor and three district nurses were attached to more than one practice. Because these nurses' experiences could vary with each different attachment setting, it was necessary for them to complete a questionnaire for each attachment. Except for table I which deals with identifying information, the remainder of the tabled results are 
based on responses from the total number of questionnaires completed.

Table 1 Number of staff involved in previous attachments

\begin{tabular}{llll}
\hline & Health visitors & District nurses & Combined group* \\
\hline Yes & 29 & 16 & 45 \\
No & 19 & 29 & 48 \\
\hline
\end{tabular}

*Total number of participants.

\section{IDENTIFYING INFORMATION}

There were 97 completed questionnaires, 48 from district nurses and 49 from health visitors. About one half of the group were "fully attached"-that is, the nurse is responsible only for the patients on the lists of specified general practitioners. ${ }^{6}$ Forty nurses worked in a "liaison" attachment where they carried responsibility for a geographical area in addition to being attached to a specified general practice. ${ }^{6}$ Eight questionnaires were received from four nurses who had more than one practice attachment. Most respondents were between 35 and 55 .

In looking at previous work experiences, some differences were noted between the district nurse and health visitor groups. Considerably fewer district nurses had worked in other attachments before their present one than had health visitors. ${ }^{1}$ District nurses also seem to stay longer with one practice than do health visitors (table 2 ), thus reflecting more mobility on the part of health visitors.

Table 2 Years in present attachment

\begin{tabular}{llcl}
\hline No of years & Health visitors & District nurses & Combined group \\
\hline$<1$ & 10 & 1 & 11 \\
$1-2$ & 12 & 5 & 17 \\
$2-4$ & 11 & 12 & 23 \\
$4-6$ & 4 & 8 & 12 \\
$6-8$ & 10 & 19 & 29 \\
$8-10$ & 1 & 2 & 3 \\
\hline
\end{tabular}

*Total number of completed questionnaires.

Most teams consisted of one district nurse, one or two health visitors, and from two to six practitioners. Some groups, however were clearly not so complete, and in 10 instances the respondents indicated that they were the only nurse member in their attachment group.

\section{PREPARATION}

Preparation for attachment has been emphasised by several writers as essential if teamwork is expected to proceed. ${ }^{17}$ Generally, a very casual approach appears to have been adopted in this area health authority. Only three respondents had attended any organised meeting between the area health authority and general practitioners (table 3 ). Twenty nurses had taken responsibility for introducing themselves to their attachment group. This somewhat disorganised approach is probably not unique to this authority, as a study in 1977 showed that there was considerable confusion between general practitioners and several area health authorities as to whether nurses were actually attached to their practice or not. ${ }^{2}$ Related to the question of preparation is that of subsequent evaluation. Obviously this was not the policy of the area health authority surveyed, as only three district nurses and one health visitor indicated that a trial period and evaluation of their attachment had occured. Of the 97 nurses, 78 had been preceded in their present attachment by a previous appointee, so perhaps formal preparation and follow up procedures were not considered necessary for successors.

Table 3 Preparation for attachment (multiple answer possible)

\section{Self introduction}

Introduction by nursing officer (NO)

Introduction by colleague

Already knew GPs

Specific discussion with GPs and NO re roles

Group meeting held by health authority re attachment

Area health authority provided orientation to attachment practice

Approached by GP

Other

\section{PHYSICAL PREMISES}

Shared premises would appear to be quite important in developing a team approach to primary care, and yet only about one third of this group of attached nurses worked from the same premises as their general practice colleagues. Twenty respondents were functioning from a base where no other members of their attachment group worked. Gilmore in 1974 noted that some of these groups were not multidisciplinary but "composed of small cells of colleagues in the same discipline."4 It seems likely that being apart from other attachment group members would naturally cause staff to strengthen their links with colleagues of their own discipline, and in many centres health visitors and district nurses were accomodated separately. There is also a possibility that the provision of shared premises may 
be a somewhat overrated factor in developing teamwork. Some respondents had no difficulty making daily or more frequent visits to their general practice attachment, although they were based elsewhere. They were expected regularly to "nip round" and were observed to be quite familiar with, and warmly welcomed by the general practice staff. Conversely, other nurses accommodated in health centres with their general practice colleagues met those colleagues relatively infrequently. One health centre was so designed that doctors and nursing staff had separate entrances, rarely saw each other, and the attitudes were considerably more distant. It was interesting to find that while 36 respondents did share premises with their general practice colleagues, 15 of these did not think that these working facilities promoted teamwork. A practical indication of this feeling was shown in the finding that of 21 nurses who attended regular team meetings, only six worked from shared facilities - that is, health centres or clinics. Thus the provision of shared facilities alone is apparently not enough, and occasionally the health centre facility seemed to accentuate rather than diminish professional divisions.

All nurses in this study were based at area health authority facilities, either a health centre or a health clinic. This was due to the present policy in this area health authority not to locate attached staff at general practices outside health centres.

\section{COMMUNICATION}

Both health visitors and district nurses contacted each other less often than they did the general practitioners. When considering the results of the total group, the frequency of communication with general practitioners was as follows: five communicated two to three times a day, for 22 it was daily; for 23 it was two to three times a week; 13 made two to three contacts a month; for three it was monthly, and for five it was every six months. The notable result in this area was the small group of nurses who had virtually no regular patterns of communication with other members of their attachment group. Two district nurses and five health visitors stated that they contacted each other no more frequently than every six months. It seems unlikely that attachment can be any more than a "paper transaction" in these cases and certainly would appear to require evaluation. Group meetings of attachment teams were held by only 21 of the 97 nurses. These meetings were found to be useful and conducive to teamwork. Nevertheless, concerns about the lack of available time and the inability of all group members to attend were expressed. Meetings were usually unstructured, without a chairman or agenda. Little awareness of the long term benefits of these meetings was indicated in the written comments about their value; most respondents seemed to find them useful as regular, reasonably frequent opportunities to communicate about immediate problems. Of the 77 nurses not already attending any sort of group meeting, 56 stated that they would like to.

\section{ROLE DEFINITION}

Respondents were asked if they thought that their skills were appropriately used by other members of the attachment group. Twenty health visitors as opposed to seven district nurses replied negatively; many commented that the preventative aspect of their work was neither understood nor appreciated by general practitioners. As this is the major component of health visitors' work it is not surprising that health visitors throughout this survey exhibited considerably less enthusiasm for attachment than did district nurses. On the other hand, almost all health visitors thought that their district nurse colleagues were supportive of their preventative work and several commented that attachment arrangements had helped in this regard; their skills were being increasingly recognised and used.

\section{PERCEPTIONS OF TEAMWORK}

Respondents were asked if they thought their attachment group functioned as a team, the definition being, "a group of people who make different contributions towards the achievement of a common goal." 5 Of the 97 respondents, 77 thought that this description applied to them. It is to be recognised that this was a non-specific description and that responses would depend on individual attitudes and interpretation. Examples of teamwork were given (table 4) and respondents were asked to tick those applicable in their case. The most frequently ticked example was "prompt action on my assessment and referrals"-71 of possible 97

Table 4 Applicable examples of teamwork (multiple possible)

\begin{tabular}{lrrr}
\hline & $H V$ & $D N$ & $C^{*}$ \\
\hline Support and back up of attachment group & 28 & 27 & 55 \\
Shared planning and delivery of care & 10 & 20 & 30 \\
Prompt action on nurses' assessment and referrals & 35 & 36 & 71 \\
Good interprofessional communication & 22 & 36 & 58 \\
Joint clinics held with GPs & 6 & 7 & 13 \\
Make joint home visits with GPs & 2 & 29 & 31 \\
Share information on new drugs, treatments & 9 & 28 & 37 \\
Advice of nurse, suggestions for patient's care requestedi17 & 41 & 58 \\
Other & 1 & - & 1 \\
None of above apply & 5 & 1 & 6 \\
\hline
\end{tabular}

"Total number of questionnaires. 
responses. In all examples, and especially those describing collaborative activities, the district nurses showed much higher levels of response than did health visitors. The nature of the district nurse's work may be the major reason for this difference. In providing "hands on" physical care for patients she is seen as an extension of the physician, dealing with any practical difficulties the ill patients may experience. For this physical and emotional support she is greatly appreciated by the patient and family who often directly or indirectly extend this gratitude to the physician as well. Because the goals of the physician and district nurse are similar, opportunities for collaboration are frequent. Twenty nine district nurses, compared with only two health visitors, regularly made joint home visits with their general practitioner colleagues. The district nurses' role is similar to the traditional nurses' image; she is perceived by the physician to be extremely useful and compatible with his view of how a nurse should function. On the other hand, the health visitor may not fit the stereotypic helpmate image. She may have a strong sense of her identity as a health promoter and educator, may decline to be concerned in any physical nursing procedures of any type, and her emphasis on preventive health may be a novel and threatening notion for the physician. Thus there may be both practical and ideological barriers to collaborative activities developing between health visitors and general practitioners.

Respondents were asked about obstacles to teamwork within their attachment group. Ten district nurses and 25 health visitors responded to this open ended query, again a fairly clear indication of how the two groups differed. Frequently mentioned problems included: no shared concept of teamwork, lack of shared premises, poor communication, indifference of general practitioner, and personality conflicts.

Despite the endorsement of the team concept few respondents had joined in any group projects or evaluation of their attachment groups' activities. Gilmore's study supports this finding as she described most teams as having developed no identifiable means of carving out their common aims, clarifying policies, or co-ordinating their work. ${ }^{4}$ Nurses did show interest in being more involved in a variety of ways with the attachment group; half the group indicated they would welcome being included in practice decisions such as hiring, and having the general practitioners involved when the area health authority selected a nurse for attachment.

\section{COMMITMENT}

Most respondents, 75 of 97 , valued their affiliation with the area health authority and did not indicate any difficulty in being attached to a general practice while employed by the area health authority. For the group of 22 who had some problems in this regard, 15 were health visitors and six were district nurses. Some examples of difficulties experienced by this group were: the general practitioner requesting nursing activities not approved by the area health authority; the general practitioners' policies regarding immunisation being in conflict with the area health authority; differing attitudes between health visitors and general practitioners in regard to health; and conflict in terms of time commitment demanded of the nurse by the general practitioner and the area health authority. Most respondents clearly valued their links with the area health authority, 35 of 97 describing this as "very important" and 49 stating it was "fairly important."

\section{PATIENT CARE}

In considering the advantages of attachment in so far as patient care was concerned, 84 thought that patients did benefit. This conclusion is not new; it has been the prevalent view for some time. Table $5 \stackrel{0}{\bar{\Phi}} \dot{\infty}$

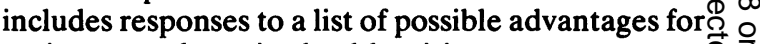
patients, and again health visitors were not so positive as were district nurses. Several health visitorso $\vec{z}$ mentioned their concern about mobile families in the inner city areas not being affiliated to a generalo응 옥 practice, and sometimes missed. A study in $1979 \leftrightarrows . \vec{\circ}$ compared "attached" and "patch" health visitor을 work and found that geographically based health" visitors had higher numbers of "no one initiated" visits and increased follow up of families not known to have a general practitioner. ${ }^{8}$ With this in mind, it may be important to re-evaluate each individual attachment group and the population it serves so that optimum use of personnel may be achieved. The final question asked nurses if they would prefer to work on a geographical rather than an attachment basis. Most clearly favoured attachment, as 82 of the 97 questionnaires showed that they were not interested in returning to geographically based work. Several

Table 5 Advantages of attachment for patients (multiple answers possible)

\begin{tabular}{lrrr}
\hline & $H V$ & $D N$ & $C^{\star}$ \\
\hline Easier access to patients when team located together & 18 & 26 & 44 \\
Referrals faster and more efficient & 36 & 40 & 76 \\
Consistent advice, care given to patients by team & 18 & 30 & 48 \\
Patients think there iscooperation betweennurses and GPs 28 & 46 & 74 \\
Patients pass information via nursing staff to GPs & 26 & 44 & 70 \\
Continuity of care is improved by good communications 25 & 40 & 65 \\
Other & 1 & 0 & 1 \\
None of the above apply & 2 & 0 & 2 \\
\hline
\end{tabular}

*Total number of questionnaires. 
health visitors, however, qualified their responses, stating that they preferred attachment but wished it functioned more as a team. Another suggestion from several respondents was that general practitioners limit their practices to well defined smaller areas to reduce nurses' travelling time and increase their ability to identify new families before problems developed.

\section{DISCUSSION}

This study has looked at the development of attachment schemes and aspects of teamwork as experienced by a group of attached health visitors and district nurses. Clearly the findings are limited by the restriction of this survey to one area health authority. Variations in participants' recall abilities and difficulties in assessing attitudes and feelings are also major limitations in this type of questionnaire survey.

While most nurses in this survey preferred attachment to a geographical method of working their responses also reflected some scepticism and in a few cases flat denial in so far as the reality of the primary care team was concerned. Part of the problem may be simply the ambiguity of primary care itself, as it is an area where there are many opportunities for sharing in patient care, but also more confusion in terms of tasks, roles, and leadership. The British model creates further difficulties as there are two levels of management concerned, thus making it more difficult for a clear sense of direction to be developed and pursued by the parties concerned. In only three instances did the area health authority and general practice physicians attend any preparatory meeting before attachment, and further opportunities for group meetings occurred in fewer than one third of attachments surveyed. Where such meetings regularly took place they frequently focused on immediate problems of patient care and rarely had any organisation or inclination to consider long term or planning issues.

Another problem has been the lack of resources effectively to implement attachment. Half the nurses surveyed had additional duties beyond their primary attachment arrangement, and in 10 instances the primary care teams were incomplete with only one nurse member. Area health authorities may have had to compromise the development of attachment teams in an attempt to maintain some of the traditional geographical services, especially in disadvantaged urban areas.

Physical premises, even relatively new health centres, have not been designed with teamwork in mind and in about one fifth of nurses surveyed, team members were based individually at different locations. It is therefore not surprising that disillusionment has developed in view of the practical difficulties many attachment groups have experienced.

While not a new finding, it is interesting that health visitors continue to experience difficulties in interpreting and finding support for the preventative nature of their work within the primary care team. Obviously, educators, employers, and all health care personnel expected to work in a team must seek new methods of addressing this problem if old antagonisms and suspicions are to be resolved.

Undoubtedly the need for good primary care will continue to grow and future community health services will be pressed to meet greater demands. Whether all needs can be best met by general practice attachment arrangements is not clear, and participants in this study identified groups who were not being well served in this respect. If the development of good primary care is to proceed a flexible and positive policy will be required of area health authorities. The support of many other resources-that is, general practitioners, patient groups, nursing staff, educational institutions, etc-will be essential but it will be the area health authorities who must take the initiative and offer direction and coordination to these groups. A first step would seem to be an objective assessment of present attachment schemes to identify existing problems and seek solutions. Only when there is awareness of what is missing in teamwork can an organised and constructive pursuit of it begin. Just at completion of this study some participants met senior nursing staff to consider problems they were experiencing in their attachment arrangement. Perhaps this was coincidental; however, it has been shown before that the process of "looking" can be a facilitating action in itself. Finally, it must be remembered that primary care teams or attachment arrangements, or both, are potentially a means to improved health care, not an end in themselves. As such, they should be periodically evaluated and considered individually to see that the health care needs of the public are being economically and effectively served.

I wish to acknowledge help and advice from Miss Jean King, divisional nursing officer, Leeds Area Health Authority, western district; Dr J H Walker, community and family medicine, University of Newcastle upon Tyne; Mr John Webster, department of computer science and mathematics, Leeds Polytechnic; and Mrs Doris Weightman, health care research unit, University of Newcastle upon Tyne. 


\section{References}

${ }^{1}$ Walker JH, McClure LN. Community nurses' view of general practice attachment. $\mathrm{Br}$ Med J 1969: iii:584-7.

${ }^{2}$ Reedy BLEC. Primary care. In: Fry J, ed. Teamwork in primary care - a conspectus from primary care. London: Heinemann Medical Books Ltd, 1980: 108-39.

${ }^{3}$ Hunt M. Team work conference 1978. Community Outlook, Nursing Times 1978 Dec 14; 368-71.

${ }^{4}$ Gilmore M, Bruce N, Hunt M. The work of the nursing team in general practice. London: Council for the Education and Training of Health Visitors, 1974.
${ }^{5}$ Tongue D. Teamwork conference 1978. Community Outlook, Nursing Times 1978 December 14; 368-71.

- Anderson JAD, Draper P, Kincaid IT, Ambler MC. Attachment of community nurses to general practices: a following study. $\mathrm{Br} \mathrm{Med} J$ 1970; iv: 103-5.

${ }^{7}$ Friend P. Nursing in primary care. Nursing Mirror 1977 July $14 ; 145,41-2$.

${ }^{8}$ Walsworth JH. Patch work. Health Visitor 1979; 52: 307-10. 